\title{
Gastric cancer: predictors of recurrence when lymph-node dissection is inadequate
}

\section{Esther Uña}

\author{
Address: Medical Oncology Service, Clinical University Hospital, Valladolid, Spain
}

Email: Esther Uña - aunacid@hotmail.com

Published: 17 September 2009

World Journal of Surgical Oncology 2009, 7:69 doi:10.1186/1477-7819-7-69

This article is available from: http://www.wjso.com/content/7/l/69

(c) 2009 Uña; licensee BioMed Central Ltd.

This is an Open Access article distributed under the terms of the Creative Commons Attribution License (http://creativecommons.org/licenses/by/2.0), which permits unrestricted use, distribution, and reproduction in any medium, provided the original work is properly cited.
Received: 26 June 2009

Accepted: 17 September 2009

\begin{abstract}
Background: The TNM classification (sixth edition) requires at least 15 lymph nodes to be examined to allow an accurate staging. However, in our environment, only $20 \%$ of patients have the recommended minimum of 15 nodes removed.
\end{abstract}

Purpose: To evaluate clinicopathological predictors of recurrence in patients with gastric cancer undergoing radical resection with an inadequate number of lymph nodes examined.

Methods: I0I patients were included in this retrospective cohort. We evaluated age, gender, tumoral location, Borrmann type, Lauren histotype, type of gastrectomy, grade, invasion depth of tumor, lymph node involvement, ratio between metastatic and total number of excised lymph nodes keeping $20 \%$ as the cutoff value (LNR) and adjuvant treatment. The association between these variables and recurrence was investigated by using univariate methods and multivariate logistic regression analysis.

Results: Median (range) age was 63 years (44-85). 63\% males, 37\% females. Median follow-up time for the whole patients population was 36 months (10-104). Median number of lymph nodes retrieved was $6(0-14)$. Recurrence: 50 of 101 cases $(49,6 \%) ; 41$ hematogeneus dissemination, 9 locoregional recurrences. The following factors were found to be correlated with the recurrence risk: tumoral location, invasion depth of tumor, lymph node involvement and LNR. A multivariate analysis revealed that depth of invasion [odds ratio (OR) 2.80 , 95\% confidence interval (Cl) I.03$7.58, \mathrm{P}=0.04$ ] and $\mathrm{LNR}(\mathrm{OR} 2.34,95 \% \mathrm{Cl} \mathrm{I} .05-5.2 \mathrm{I}, \mathrm{P}=0.03)$ were independent risk factors for recurrences of gastric cancer. Median time to recurrence: 16 months (2-50). $82 \%$ of recurrences occurred within the first two years after surgical treatment. The estimated cumulative risk of recurrence at five years: $61 \%$ in the whole patients population, with serosal invasion and LNR > and $<20 \%$ was $82 \%$ and $44 \%$, without serosal invasion $73 \%$ and $39 \%$ respectively.

Conclusion: Invasion depth of tumor and LNR were independent predictors of recurrence in gastric cancer after potentially curative resection with an inadequate number of lymph nodes examined.

\section{Correspondence}

Metastasis of the lymph node (MLN) is one of the most important prognostic factors in gastric cancer [1].
Although Aurello et al. [2] have indicated that the number of nodes necessary to conclude NO may vary according to the depth of tumor invasion (T), the TNM classification 
(International Union Against Cancer, sixth edition) requires the retrieval and analysis of at least 15 lymph nodes for accurate staging. However, in most cases, the number of nodes dissected is smaller and only 20 to $30 \%$ of the patients have the recommended minimum dissection of 15 nodes.

Although previous studies have indicated that the lymphnode ratio (LNR), which is defined as the ratio of the number of MLN to the total number of nodes found during pathological examination, is a powerful independent prognostic factor $[3,4]$ with significant superiority in minimizing "stage migration" for patients with more than 15 nodes evaluated, it remains controversial whether this result is applicable to patients with inadequate staging [5]. Many published studies report different cut offs for LNR, but the consensus value seems to be $20 \%$ [6].

We carried out an institutional retrospective study to investigate the relationship between classical clinicopathological features and LNR (using $20 \%$ as the cut off value) and the prognosis in patients with gastric cancer who underwent an apparently radical resection but who had an insufficient number of lymph nodes retrieved (and, therefore, were inadequately staged).

One hundred and one patients were included in the study from 2003 to 2006. The median age was 63 years (range, $44-85$ years) and $63 \%$ of patients were male. The median follow-up time was 36 months (range, 10-104 months) and the median number of lymph nodes analyzed was six (range, 0-14 nodes). Recurrence was detected in 50 out of 101 cases $(49,6 \%), 41$ patients presented hematogenous dissemination as the main location (20 of them presented also locoregional recurrence with lymph nodes involved in 13 patients), and nine patients had only locoregional recurrence (see Table 1). The high recurrence rate observed in this population could be explained by the selection process, which was based on limited lymph node dissection and could lead to an increase in the likelihood of understaging. Many studies have indicated that the number of metastatic nodes in patients with radically resected gastric cancer increases with the number of lymph nodes removed [7].

The following factors were correlated with the recurrence risk: tumoral location, invasion depth of the tumor, lymph-node involvement ( $\mathrm{pN})$, and LNR.

A multivariate analysis of our data revealed that depth of invasion [odds ratio (OR), 2.80; 95\% confidence interval (CI), 1.03-7.58; $P=0.04]$ and LNR (OR, 2.34; 95\% CI, $1.05-5.21 ; P=0.03$ ) were independent risk factors for the recurrence of gastric cancer.
Table I: Specific sites of gastric cancer recurrence in our population.

\begin{tabular}{ll}
\hline Locoregional & Number of patients \\
\hline Lymph nodes & 5 \\
\hline Anastomosis & 2 \\
\hline Gastric bed & 2 \\
\hline Distant & Number of patients \\
\hline Peritoneal carcinomatosis & 18 \\
\hline Liver & 11 \\
\hline Lung & 8 \\
\hline Bones & 3 \\
\hline Pleura & 1 \\
\hline
\end{tabular}

The median time to recurrence was 16 months (range, 250 months). Eighty-two percent of recurrences occurred within the first two years after surgical treatment. The estimated cumulative risk of recurrence at five years was $61 \%$ in the whole population; in the case of serosal invasion and $\mathrm{LNR}>$ and $\leq 20 \%$, this risk was $82 \%$ and $44 \%$, respectively; without serosal invasion, the risk was $73 \%$ and $39 \%$, respectively with $\mathrm{LNR}>$ and $\leq 20 \%$.

Although we did not apply any specific method to select the LNR cut off, we nevertheless obtained an interesting and significant result considering $20 \%$ as the cut off most frequently used. It is clear that the fewer the nodes examined, the lower was the accuracy of the prognostic system.

Our study revealed that depth of tumor invasion and LNR with a $20 \%$ cutoff value were independent and significant predictors of recurrence in gastric cancer after potentially curative resection with examination of an inadequate number of lymph nodes.

\section{Competing interests}

The author declares that she has no competing interests.

\section{References}

I. Hidaka H, Eto T, Maehara N, Jimi S, Hotokezaka M, Chijiiwa K: Comparative effect of lymph node metastasis classified by the anatomical site or by the number of nodes involved on prognosis of patients with gastric cancer. Hepatogastroenterology 2008, 55(88):2269-2272

2. Aurello P, D'Angelo F, Rossi S, Bellagamba R, Cicchini C, Nigri G, Ercolani G, De Angelis R, Ramacciato G: Classification of Iymph node metastases from gastric cancer: comparison between $\mathrm{N}$-site and $\mathrm{N}$-number systems. Our experience and review of the literature. Am Surg 2007, 73:359-366. 
3. Xu DZ, Geng QR, Long ZJ, Zhan YQ, Li W, Zhou ZW, Chen YB, Sun $X W$, Chen G, Liu $Q$ : Positive lymph node ratio is an independent prognostic factor in gastric cancer after D2 resection regardless of the examined number of lymph nodes. Ann Surg Oncol 2009, 16(2):319-326.

4. Persiani R, Rausei S, Biondi A, Boccia S, Cananzi F, D'Ugo D: Ratio of metastatic lymph nodes: impact on staging and survival of gastric cancer. Eur J Surg Oncol 2008, 34(5):519-524.

5. Sun Z, Zhu GL, Lu C, Guo PT, Huang BJ, Li K, Xu Y, Li DM, Wang $\mathrm{ZN}, \mathrm{Xu} H \mathrm{HM}$ : The impact of $\mathbf{N}$-ratio in minimizing stage migration phenomenon in gastric cancer patients with insufficient number or level of lymph node retrieved: results from a Chinese mono-institutional study in 2159 patients. Ann Oncol 2009, 20(5):897-905.

6. Siewert JR, Bottcher K, Stein HJ, Roder JD: Relevant prognostic factors in gastric cancer: ten-year results of the German Gastric Cancer Study. Ann Surg 1998, 228:449-46I.

7. Marchet A, Mocellin S, Ambrosi A, Morgagni P, Garcea D, Marrelli D, Roviello F, de Manzoni G, Minicozzi A, Natalini G, De Santis F, Baiocchi L, Coniglio A, Nitti D, Italian Research Group for Gastric Cancer (IRGGC): The ratio between metastatic and examined lymph nodes ( $\mathrm{N}$ ratio) is an independent prognostic factor in gastric cancer regardless of the type of lymphadenectomy. Results from an Italian multicentric study in 1853 patients. Ann of Surg 2007, 245(4):543-552.

Publish with Bio Med Central and every scientist can read your work free of charge

"BioMed Central will be the most significant development for disseminating the results of biomedical research in our lifetime. "

Sir Paul Nurse, Cancer Research UK

Your research papers will be:

- available free of charge to the entire biomedical community

- peer reviewed and published immediately upon acceptance

- cited in PubMed and archived on PubMed Central

- yours - you keep the copyright 